SINAI Journal of Applied Sciences 10 (2) 2021 219-228

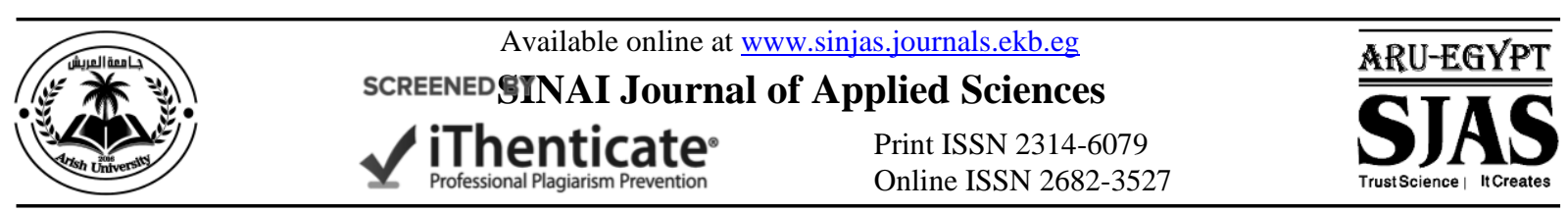

\title{
PRODUCTION AND EXPORT STATUS OF DATE PALM CROP IN EGYPT
}

\author{
Hosam El-Din Y. Tafily ${ }^{1 *}$, Soad A. Ibrahim ${ }^{1}$, R.M. Hefny ${ }^{1}$ \\ 1. Dept. Econ. and Rural Develop., Fac. Environ. Agric. Sci., Arish Univ., Egypt.
}

\begin{tabular}{l} 
ARTICLE INFO \\
\hline Article history: \\
Received: $10 / 07 / 2021$ \\
Revised: $20 / 09 / 2021$ \\
Accepted: $11 / 10 / 2021$ \\
Available online: $11 / 10 / 2021$ \\
\hline Keywords: \\
Date Palm, \\
Export, \\
production, \\
Egypt \\
\\
Check for \\
updates
\end{tabular}

\begin{abstract}
The research aimed to identify the production and export situation and the most important problems facing and how to overcome them. Developing a strategy to benefit from Date Palm crop. The problem of the research was limited to the fact that Egypt has a suitable climate for Date Palm cultivation, which provides an opportunity to produce large quantities of the Date Palm crop with high quality. However, this advantage is not exploited, as Egypt's exports of Dates reached about 13.1 thousand tons during the period (20002017), which represents a very low percentage of the total production. This indicates the need to know the production status of the Date Palm crop, as well as the most important problems facing its export. In achieving its objectives, the research relied on methods of descriptive and quantitative economic analyses to describe the various economic variables under study as well as estimating the general time trend equations. The study also used many methods of economic analysis and its tools such as percentages, arithmetic average in addition to using simple regression equations. In achieving its objectives, the research also relied on primary data through a questionnaire form and secondary office data issued by the Central Agency for Public Mobilization and Statistics. The research recommends the necessity of making use of the Date Palm crop by working to export most of its production while taking into account protection from insects that infect Date Palm.
\end{abstract}

$$
\begin{aligned}
& \text { من محصول البلح حو الي } 13.1 \text { ألف طن خلال الفترة من }
\end{aligned}
$$

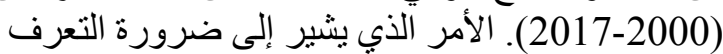

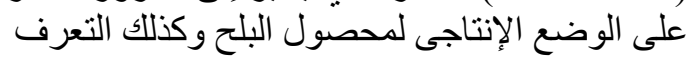

$$
\begin{aligned}
& \text { على أهم الششاكل التى تو اجه تصديره. (سليم، 2008) } \\
& \text { أهداف البحث } \\
& \text { استهدف البحث بصفة عامة در اسة الأوضاع الإنتاجية }
\end{aligned}
$$

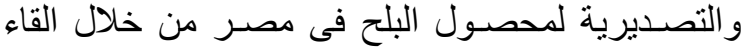

$$
\begin{aligned}
& \text { الضوء على الأهداف الفرعية التالية: } \\
& \text { 1.دراسة تطور الوضع الراهن لمحصول البلح في } \\
& \text { مصر. } \\
& \text { 2. در اسة المؤشر ات الإنتاجية لنخيل البلح بمناطق مصر }
\end{aligned}
$$

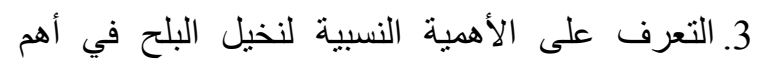

$$
\begin{aligned}
& \text { محافظات جمهورية مصر الأهربية العبية لنيل } \\
& \text { 4. مؤشر ات صادر ات وواردات مصر الي العالم الخارجي لئ لئ } \\
& \text { من البلح. } \\
& \text { مشكلة البحث }
\end{aligned}
$$

\section{مقدمة}

\footnotetext{
* Corresponding author: E-mail address: salemhossam827@gmail.com https://doi.org/10.21608/sinjas.2021.85170.1032

(C) 2021 SINAI Journal of Applied Sciences. Published by Fac. Environ. Agric. Sci., Arish Univ. All rights reserved.
} 
1.80\% من المتوسط السنوي العام وتثير التقديرات أن

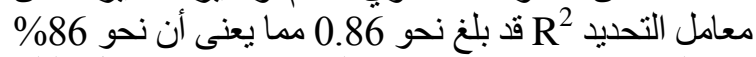

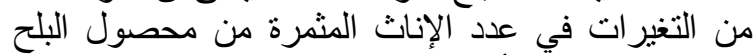

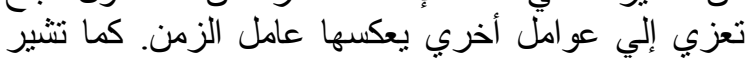

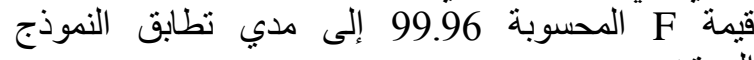

المستخدم.

\section{الإنتاجية الفدانية من محصول البلح}

تنثير النتائج الواردة بجدول 1 أن الإنتاجية الفدانية من من الباجية

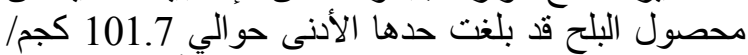

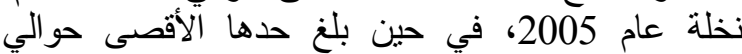

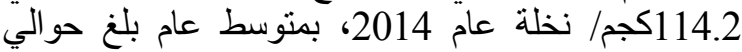
109.12 كجم/ نخلة. كما تثير تقديرات المعادلة المبلة رقم 3

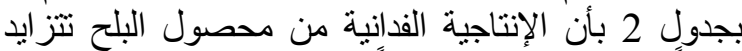

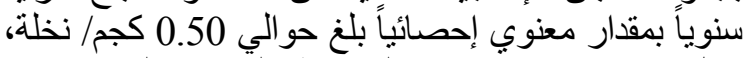

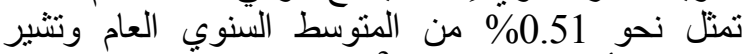
التقدير ات أن معامل التحديد أن نحو 50\% من التخير ات في الإنتاجية الفدانية من النخيل

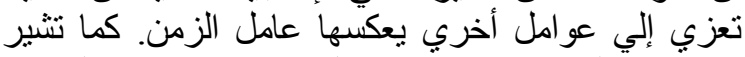

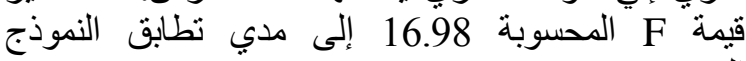

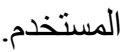

\section{الإنتاج الكلي من البلح الطازج}

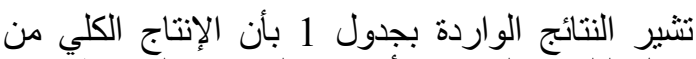

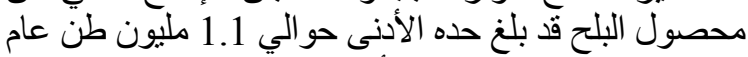

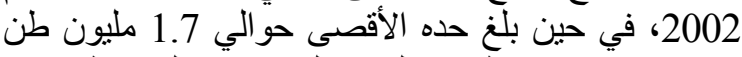

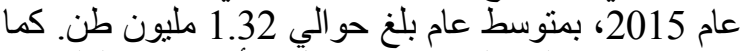

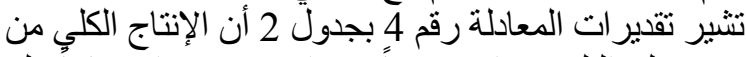

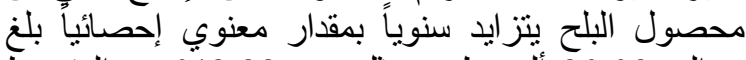

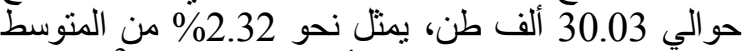

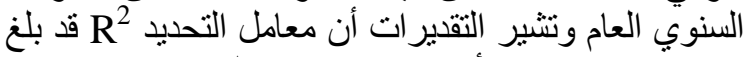

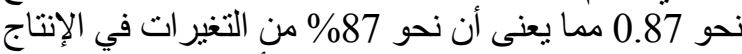

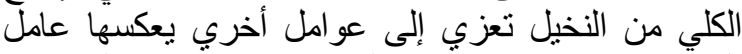

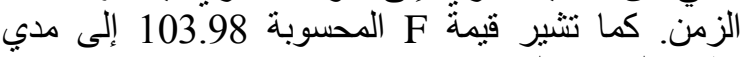
تطابق النموذج المستخدم.

\section{المؤشرات الإنتاجية لنخيل البلح بمناطق مصر المر

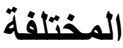

يوضح جدول 3 المؤشر ات الإنتاجية لنخيل البلح بمناطق مصر المختلفة خلال عام (2017/2016) ومنة ينتين النين أنين

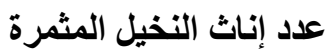

تحتل محافظات الوجه البحري المرتبة الأولي من حيث عدد إناث النخيل و البالغة حوالي 4.9 مليون نظلة التبة، تمثل نحو \%35.9 من جملة عدد إناث النخيل، في حين حين تحتل محافظات مصر الوسطي المرتبة الثانية من حيث فيث عدد إناث

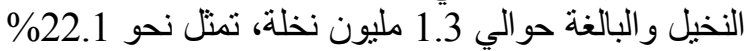

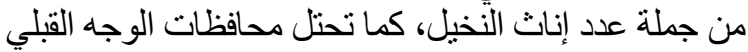

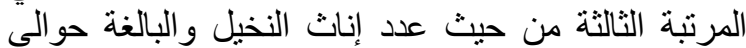
2.65 مليون نخلة، تمثل نحو 19.5\% من من الإجمالي.
5. القاء الضوء على أهم المشاكل الإنتاجية والتسويقية التى تو اجه محصول نخيل البلح وكيفية التخلب عليها.

6. در اسة استر اتيجية تطوير قطاع النخيل فى مصر الطريقة البحثية

اعتمد البحث في تحقيق أهدافه على أساليب التحليل

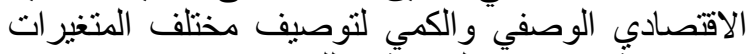

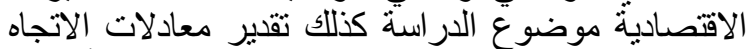

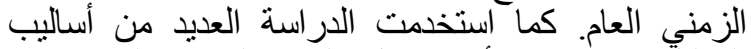

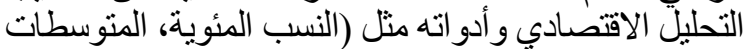
الحسايية). هذا إلى جانب استخدام معادلات الانحدار البسيط.

\section{مصادر جمع البيانات}

اعتمد البحث في تحقيق أهدافه على البيانات الأولية وذلاتك

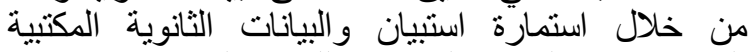

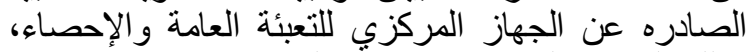

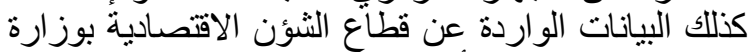
الزر اعة واستصلاح الأر اضي.

\section{النتائج ومناقشتها}

\section{الوضع الإنتاجي الراهن لمحصول البلح المساحة الكلية}

تشير النتائج الواردة بجدول 1 أن المساحة الكلية من الإنه

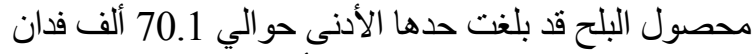
عام 2001، في حين بلغ حدها الأقصى حوالي الي 119.70

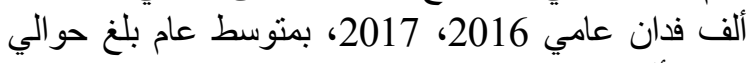

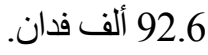

كما نتير تقديرات المعادلة رقم (1) بجدول 2 أن أن

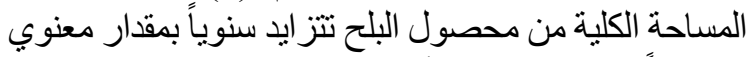

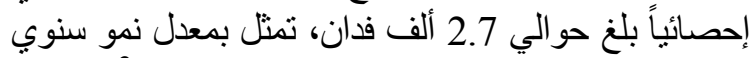
مقداره 3.4\% و تنثير التقديرات أن معامل التحديد

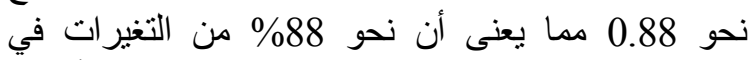
المساحة الكلية لمحصول البلح تعزي إلى على عوامل أخري

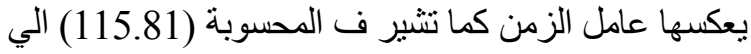
مدي تطابق النموذج المستخدم لطبيعة موضع البحث.

\section{عدد إناث النخيل المثمرة}

تشير النتائج الواردة بجدول 1 بأن عدد إناث النخيل المثمرة من البلح قد بلغت حدها الأنىى حوالي بلي 10200.00

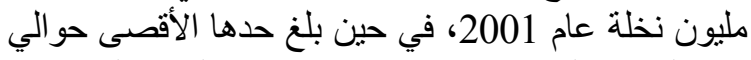
15 مليون نخلة عام 2015، بمنوسط عام عام بلغ حو الي 12.1

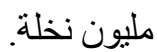

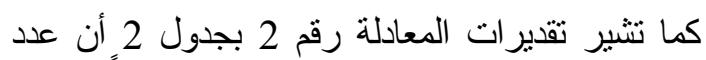

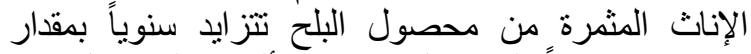

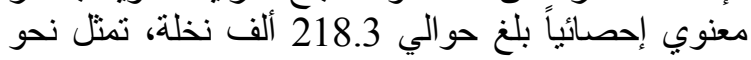


Tafily, et al. | SINAI Journal of Applied Sciences 10 (2) 2021 219-228

\begin{tabular}{|c|c|c|c|c|}
\hline الإلتـاج الكلي & (كجم/ نظلة) & عدد الإناث المثمرة & (ألف فساحة الكلية & السنة \\
\hline 1113.27 & 108.83 & $10200 \cdot 00$ & 70.1 & 2001 \\
\hline 1090.00 & 105.03 & 10378.36 & 70.52 & 2002 \\
\hline 1121.89 & 104.50 & 10735.65 & 78.07 & 2003 \\
\hline 1166.18 & 104.03 & 11209.54 & 82.18 & 2004 \\
\hline 1159.69 & 101.70 & 11402.97 & 86.08 & 2005 \\
\hline 1328.72 & 111.77 & 11888.02 & 85.19 & 2006 \\
\hline 1313.70 & 109.12 & 12039.42 & 86.79 & 2007 \\
\hline 1326.13 & 108.85 & 12183.03 & 87.69 & 2008 \\
\hline 1270.48 & 104.62 & 12143.39 & 87.92 & 2009 \\
\hline 1352.95 & 111.10 & 12177.41 & 99.87 & 2010 \\
\hline 1373.57 & 112.02 & 12261.65 & 99.17 & 2011 \\
\hline 1400.07 & 111.69 & 12534.88 & 91.67 & 2012 \\
\hline 1328.47 & 108.04 & 12296.59 & 90.29 & 2013 \\
\hline 1465.03 & 114.21 & 12827.24 & 104.85 & 2014 \\
\hline 1684.92 & 112.66 & 14956.33 & 115.61 & 2015 \\
\hline 1549.26 & 113.76 & 13618.17 & 119.70 & 2016 \\
\hline 1542.11 & 113.18 & 13625.32 & 119.70 & 2017 \\
\hline 1563.69 & 110.95 & 14093.27 & 113.22 & 2018 \\
\hline 1341.67 & 109.23 & $12 \cdot 255.60$ & 92.7 & المتوسط \\
\hline
\end{tabular}

المصدر: وزارة الزراعة واستصلاح الاراضي، قطاع الثئون الاقتصادية، نشرة الاحصاءات الزيراعبة (المحاصبيل الصبفية والنيلية)، بيانات ثانوية غير منشورة، أعداد منفرقة الأحة

جدول 2. معادلات الاتجاه الزمني العام لأهم المتغيرات الاقتصادية المرتبطة بمحصول البلح في مصر خلال الفترة .2018-2001

\begin{tabular}{|c|c|c|c|c|c|}
\hline $\mathbf{F}$ & $\mathbf{R}^{2}$ & $\begin{array}{l}\text { معندل النمو \% } \\
\text { \% }\end{array}$ & المعادلة & المتغير & المعادلة \\
\hline$* * 115.81$ & 0.88 & 3.04 & $\begin{array}{c}\widehat{\mathbf{Y}}_{1}=67.79+2.74 \mathbf{t} \\
(24.60)^{* *}(10.76)^{* *}\end{array}$ & (ألف فساحة الكلية & 1 \\
\hline$* * 99.96$ & 0.86 & 1.80 & $\begin{array}{c}\widehat{\mathbf{Y}}_{2}=10182.08+218.27 \mathbf{t} \\
(43.03)^{* *}(9.99)^{* *}\end{array}$ & عدد الإناث المثمرة & 2 \\
\hline$* * 16.07$ & 0.50 & 0.51 & $\begin{array}{c}\widehat{\mathbf{Y}}_{3}=104.43+0.50 \mathbf{t} \\
(76.63) * *(4.01)^{* *}\end{array}$ & الإنتاجية الفدانية & 3 \\
\hline$* * 103.98$ & 0.87 & 2.32 & $\begin{array}{c}\widehat{\mathbf{Y}}_{4}=1056.35+30.03 \mathbf{t} \\
(33.13) * *(10.20)^{* *}\end{array}$ & (الإنتاج طن) & 4 \\
\hline
\end{tabular}

i القيمة الثقديرية للمساحة الكلية، عدد الإناث المثمرة، الإنتاجية، الانتاج الكلى من محصول البلح في مصر (ألف فدان) في المشاهدة المصدر: نتائج الحاسب الآلي للبيانات الو اردة بجدول (1). 
جدول 3. المؤشرات الإنتاجية لنخيل البلح بمناطق مصر المختلفة خلال عام (2017/2016)

\begin{tabular}{|c|c|c|c|c|c|}
\hline$(\%)$ & ألأنتاج الكلي & متوسط إنتاجية النظلة & $(\%)$ & عدد إناث النخيل المثرمرة & المناطق \\
\hline 45.2 & 699.8 & 143.4 & 35.9 & 4.9 & الوجة البحري \\
\hline 24.6 & 380.2 & 126.3 & 22.1 & 3.1 & إل الوسطي \\
\hline 14.7 & 226.8 & 85.6 & 19.5 & 2.6 & الوجه القبلي \\
\hline 84.5 & 1306.8 & 124 & 77.5 & 10.6 & جملة الوادى \\
\hline 15.5 & 241.3 & 78.9 & 22.5 & 3.1 & خارج الوادي \\
\hline 100 & 1548.1 & 113.8 & 100 & 13.6 & الاجمالي العام \\
\hline
\end{tabular}

المصدر: جُمعت وحُسبت من وزارة الزراعة واستصلاح الأراضي، الإدارة المركزية للاقتصاد الزراعي، قطاع الثُئون الاقتصادية 2018.

\section{الأهمية النسبية لنخيل البلح في أهم محافظات جمهورية مصر العربية الإية}

الأهمية النسبية لعدد إناث النخيل المثرة الثمرة

يوضح جدول 4 الأهمية النسبية لعدد إناث النخيل

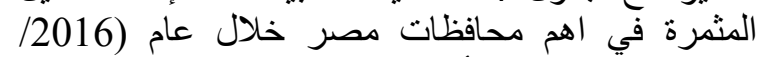

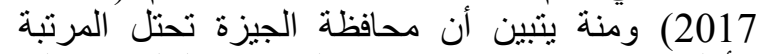

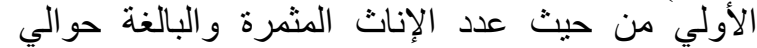

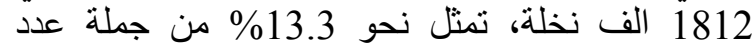
الإناث المثمرة، ثم الوادي الجديد من حيث عدد الإناث

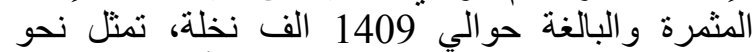
10.3\% من جملة عدد الإناث المثمرة، وتأتي الثرقية في تئية

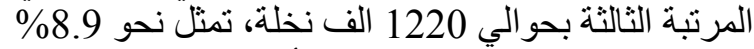

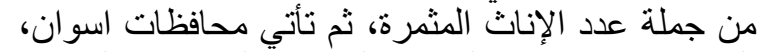

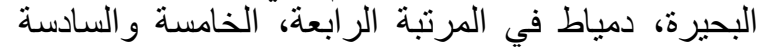
بحوالي 1219، 1062،

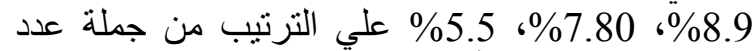

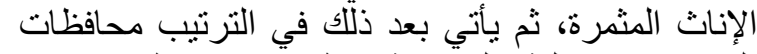

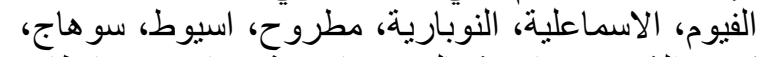

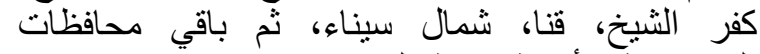

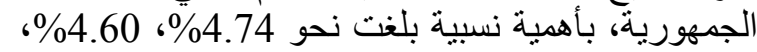

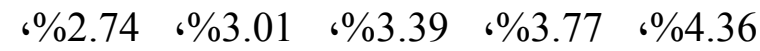

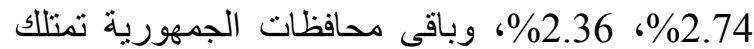
13.36\% من جملة عدد الإناث المنثرة والبالغة حوالي تلي 13618 ألف نخلة.

\section{الأهمية النسبية لمتوسط إنتاجية النظلة}

يوضح جدول 5 الأهمية النسبية لإنتاجية النخلة في الناجية

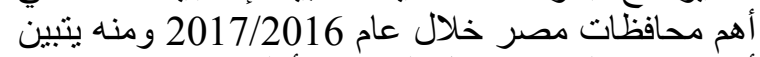

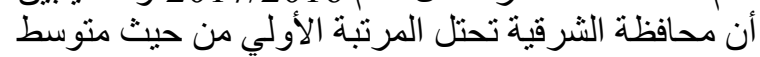

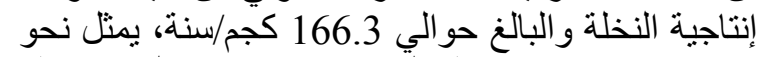

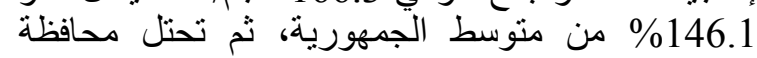
الاسماعلية المرتبة الثانبة من حيث الجيث منوسط الإنتاجية

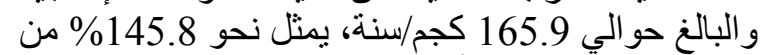
منوسط الجمهورية، وتأتي محافظة البحيرة
هذا وقد بلغ جملة عدد إناث النخيل في الوادي حوالي

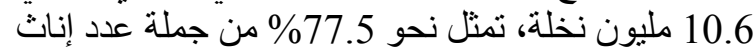

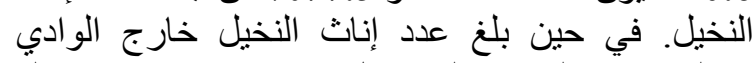

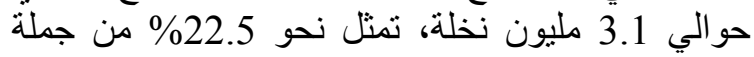
عدد إناث النخيل و البالغة حو الي 13.6 مليون نخلة.

\section{متوسط إنتاجية النخلة}

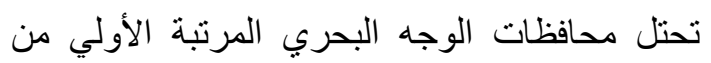

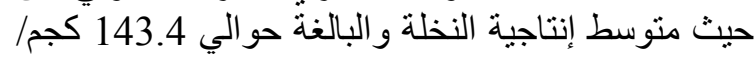

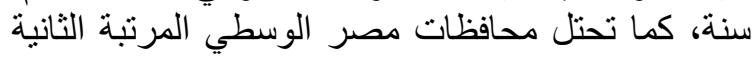
من حيث منوسط إنتاجية النخلة والبالغة حولة حوالي 126.3

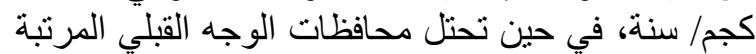

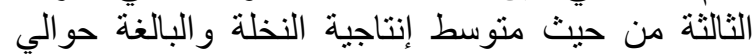
85.6 كجم/سنة. هذا وقد بلغ منتوسط إنتاجية إنتاجية النخلة في حئية الوادي حوالي 124 كجم/سنة مقابل حتوالئل حوالي 78.9 كجم/سنة لنظيرتها خارج الوادي. هذا وقد بلغ الينوسط

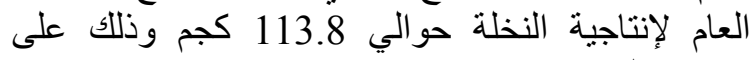
مستوي الجمهورية.

$$
\text { الإتتاج الكلي من البلح الطازج }
$$

تحتل محافظات الوجه البحري المرتبة الأولي من الإنتاج

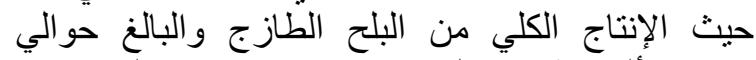

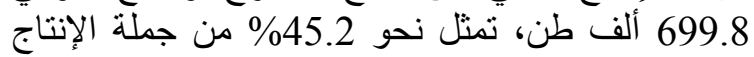
الكلي، كما تحتل محافظات مصر الوسطي المرتبة الثنانية

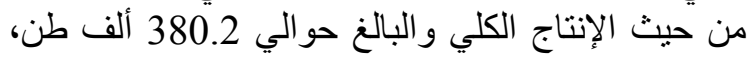

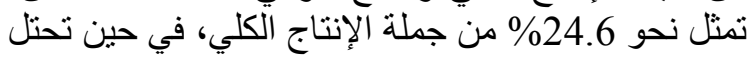

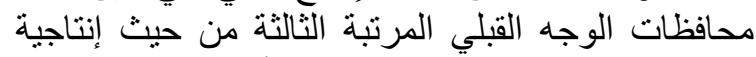

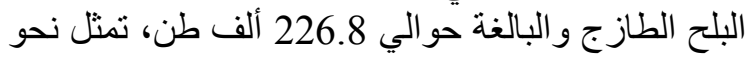
14.7\% من جملة الإنتاج الكلي. هذا وقد بلغ البخ جملة الإنتاج

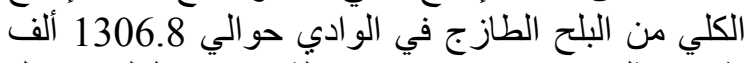

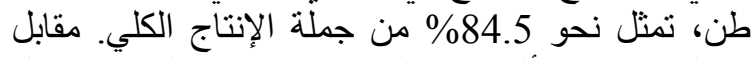

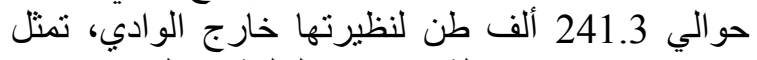

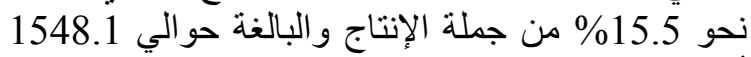
ألف طن. 
Tafily, et al. | SINAI Journal of Applied Sciences 10 (2) 2021 219-228

جدول 4. الأهمية النسبية لعدد إناث النخيل المثمرة في اهم محافظات جمهورية مصر العربية خلال عام 2017/2016.

\begin{tabular}{|c|c|c|}
\hline$(\%)$ & عدد إناث النخيل المثمرة (ألف نخلة) & المحافظة \\
\hline 13.3 & 1812 & الجيزة \\
\hline 10.3 & 1409 & الوادي الجديد \\
\hline 8.9 & 1220 & \\
\hline 8.9 & 1219 & اسوان \\
\hline 7.80 & 1062 & البحيرة \\
\hline 5.5 & 758 & دمياط \\
\hline 4.74 & 645 & الفيوم \\
\hline 4.60 & 626 & الاسماعلية \\
\hline 4.36 & 594 & التوبارية \\
\hline 3.77 & 514 & و \\
\hline 3.39 & 462 & اسيوط \\
\hline 3.01 & 410 & سوهاج \\
\hline 2.74 & 373 & كفر \\
\hline 2.74 & 373 & قنا \\
\hline 2.36 & 321 & شمال سيناء \\
\hline 13.36 & 1820 & باقي المحافظات \\
\hline 100 & 13618 & جملة الجمهورية \\
\hline
\end{tabular}

جدول 5. الأهمية النسبية لإنتاجية النظلة في أهم محافظات جمهورية مصر العربية خلال عام 2017/2016.

\begin{tabular}{|c|c|c|}
\hline (\%) من متوسط الجمهورية & متوسط إنتاجية النخلة (كجم/سنة) & المحافظة \\
\hline 146.1 & 166.3 & الشرقية \\
\hline 145.8 & 165.9 & الاسماعلية \\
\hline 139.2 & 158.4 & البحيرة " \\
\hline 114.6 & 130.4 & كفز الشيخ \\
\hline 112.9 & 128.5 & الجيزة \\
\hline 109.1 & 124.2 & الفيوم \\
\hline 105.54 & 120.1 & دمياط \\
\hline 81.90 & 93.2 & أسيوط \\
\hline 81.20 & 92.4 & سوهاج \\
\hline 79.09 & 90.0 & اسوان \\
\hline 79.09 & 90.0 & مطروح \\
\hline 75.13 & 85.5 & النوبارية \\
\hline 71.35 & 81.2 & الوادي الجديد \\
\hline 54.13 & 61.6 & قنا " ق \\
\hline 54.13 & 61.6 & شمال سيناء \\
\hline 150.62 & 171.4 & باقي المحافظات \\
\hline 100 & 113.8 & المتّوسط العام \\
\hline
\end{tabular}


وتوضح المعادلة رقم 5 بجدول 8 الاتجاه الزمني العام

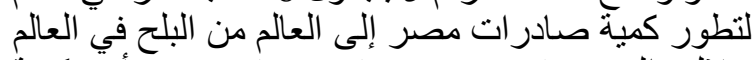

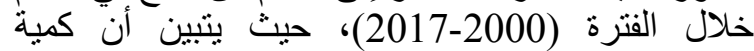
صادرات مصر إلى العالم من البلح تنز ايد سنويا بمقدار

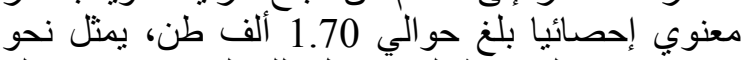

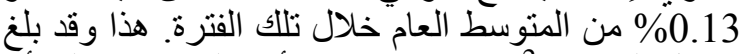

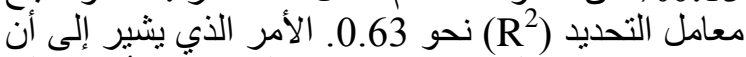

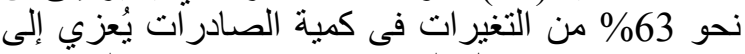

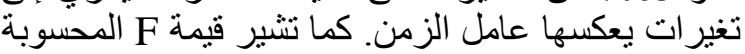

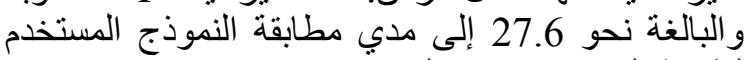
لطبيعة البيانات موضع القياس.

\section{تطور قيمة صادرات مصر الي العالم الخارجي}

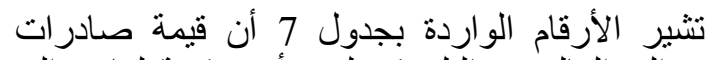

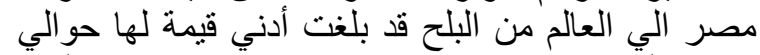

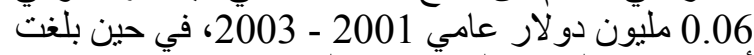

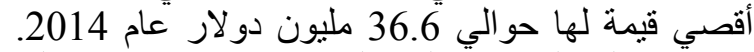
هذا وقد بلغ المتوسط العام لقيمة صلادرات دلات مصر إلى دلى العالم من البلح حوالي 15.1 مليون دولار لإن خلال الفترة 2017-2000

وتوضح المعادلة رقم 6 بجدول 8 الاتجاه الزمني العام لنطور قيمة صادرات مصر إلى العالم من البلح خلال الفئل الفترة

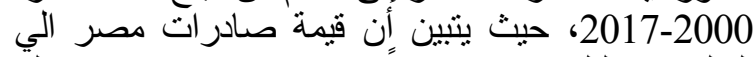

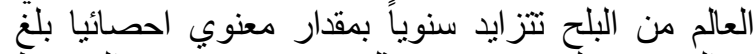

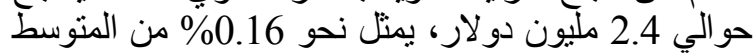

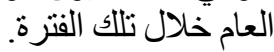

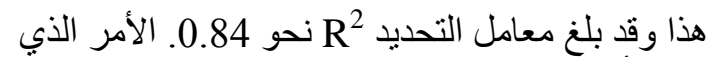

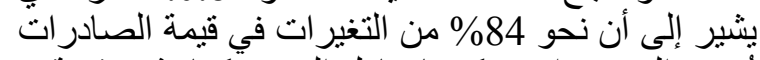

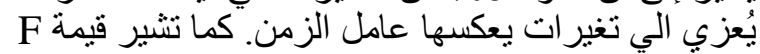

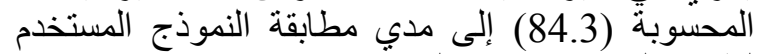
لطبيعة البيانات موضع القياس.

$$
\text { مؤشرات الواردات }
$$

\section{تطور كمية واردات مصر من العالم الخارجي الواتي}

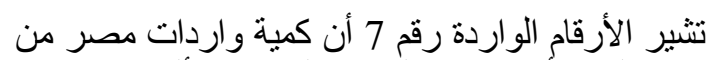

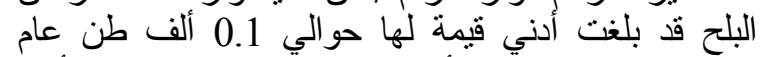

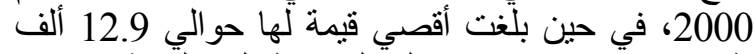

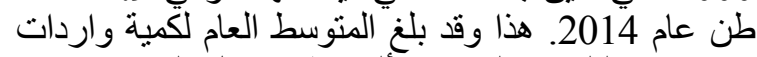
مصر من البلح حو الي 2.8 ألف طن خلال الفترة 2000-

وتوضح المعادلة رقم 7 بجدول 8 الاتجاه الزمني العام

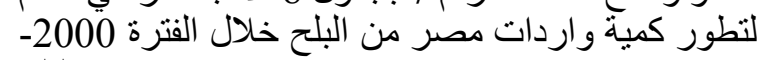

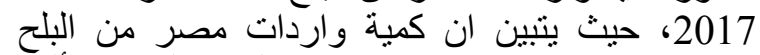

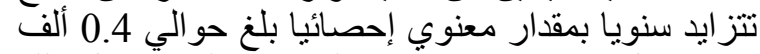

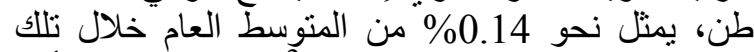

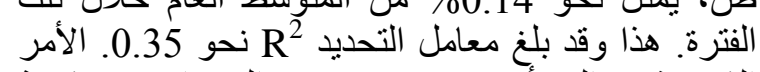

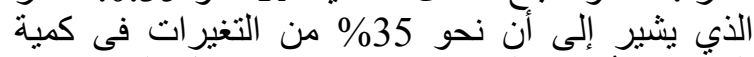

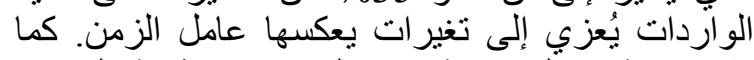
تثير قيمة F ألمحسوبة 8.7 إلى مدي مطابقة النموذج المستخدم لطبيعة البيانات موضع القياس.
في المرتبة الثالثة بحوالي 1388.4 كجم/سنة، تمثل نحو

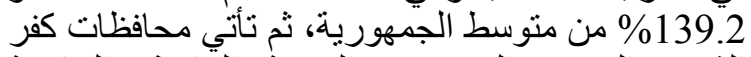

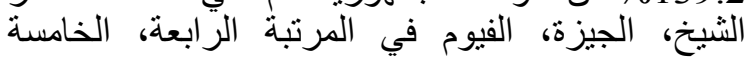

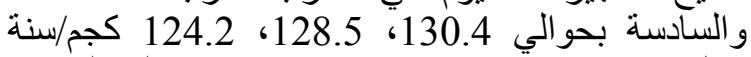

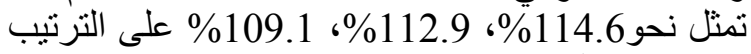

من منوسط الجمهورية.

ثم يأتي بعد ذلك في الترتيب محافظات دمياط، أسيوط،

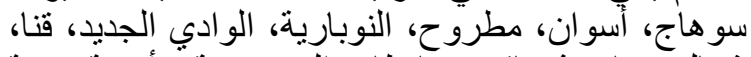

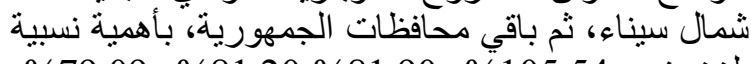

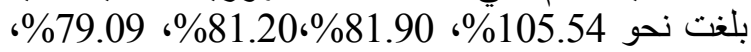

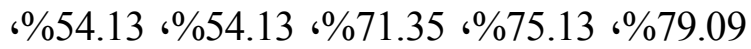
150.62\% من المنوسط العام للإنتاجية والبالغ حوالي (13.8 - كجم/سنة.

\section{الأهمية النسبية للإنتاج الكلي من البلح الطازج}

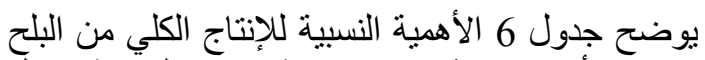

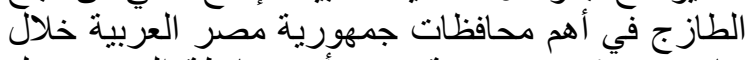

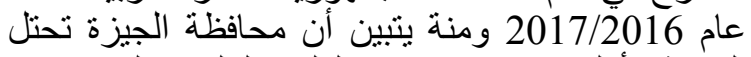
المرنبة الأولي من حيث الإنتاج الكلي و البالغ حو التي 232.6

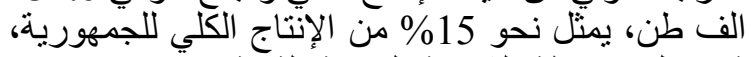

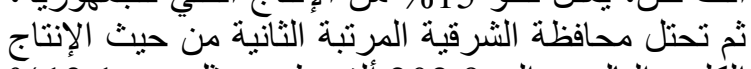

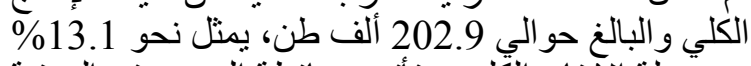
من جملة الإلتناج الكلي، وتأتي محافظة البحيرة في المرتبة

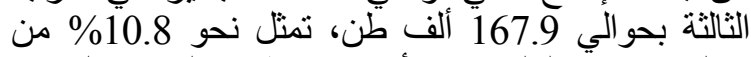

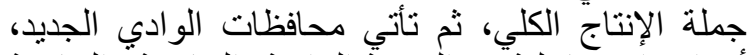

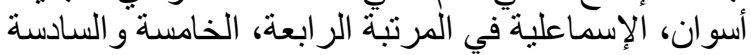

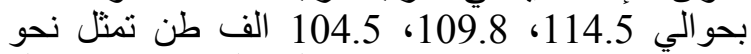

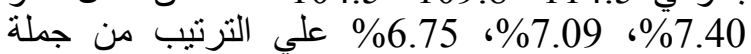

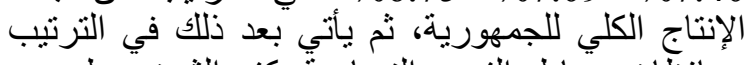

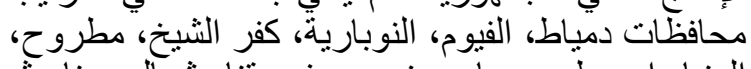

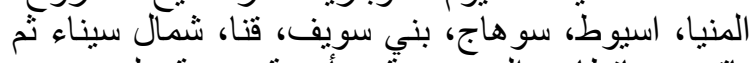

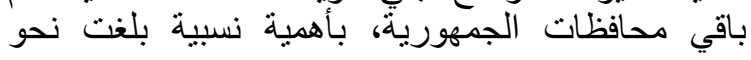

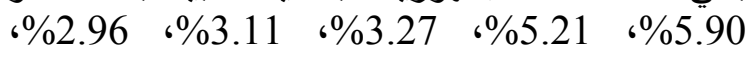
$\begin{array}{llllll}6 \% & 6 \% 2.47 & 6 \% 2.81\end{array}$ 1.27\%، \% \% \% \% \% \% المتوسط العام للإنتاج الكلي و البالغ حو الي 1548.1 ألف طن. الخأشرات صنادرات والبلح

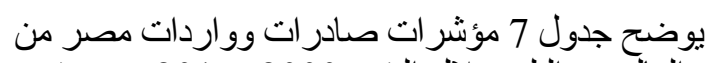

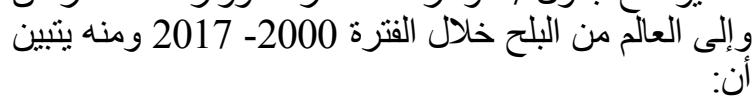

$$
\text { مؤشر ات الصادرات }
$$

\section{تظور كمية صادرات مصر الي العالم الخارجي}

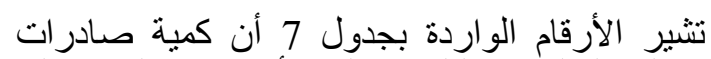

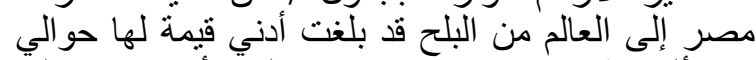

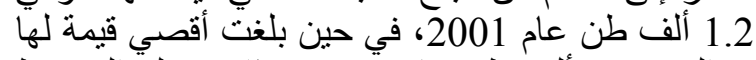

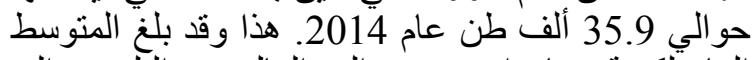
العام لكمية صادر ات مصر إلى اللى العالم من البلح حوالي الئي 13.1 ألف طن خلال الفترة 2000-2017. 
Tafily, et al. | SINAI Journal of Applied Sciences 10 (2) 2021 219-228

جدول 6. الأهمية النسبية للإنتاج الكلي في أهم محافظات جمهورية مصر العربية خلال عام (2017/2016)

\begin{tabular}{|c|c|c|}
\hline$(\%)$ & الإتتاج الكلي (ألف طن) & المحافظة \\
\hline 15 & 232.6 & الجيزة \\
\hline 13.1 & 202.9 & الشرقية \\
\hline 10.8 & 167.9 & البحيرة \\
\hline 7.40 & 114.5 & الوادي الجديد \\
\hline 7.09 & 109.8 & اسوان \\
\hline 6.75 & 104.5 & الاسماعلية \\
\hline 5.90 & 91.3 & دمياط \\
\hline 5.21 & 80.7 & الفيوم \\
\hline 3.27 & 50.6 & النوبارية \\
\hline 3.11 & 48.2 & كفر الشيخ \\
\hline 2.96 & 45.9 & مطروح \\
\hline 2.81 & 43.5 & المنيا \\
\hline 2.77 & 42.9 & اسيوط \\
\hline 2.45 & 37.9 & سوهاج \\
\hline 1.51 & 23.4 & بني سويف \\
\hline 1.47 & 22.8 & قنا \\
\hline 1.27 & 19.7 & شمال سيناء \\
\hline 7.04 & 109.0 & باقي المحافظات \\
\hline 100 & 1548.1 & جملّة الجمهورية \\
\hline
\end{tabular}

جدول 7. صادرات وواردات مصر إلى العالم من محصول البلح خلال الفترة (2000-2017)

\begin{tabular}{|c|c|c|c|c|}
\hline \multicolumn{2}{|c|}{ الواردات } & \multicolumn{2}{|c|}{ الصادرات } & \multirow[t]{3}{*}{ السنة } \\
\hline قيمة & كمية & قيمة & كمية & \\
\hline مليون دولار & ألف طن & مليون دولار & ألف طن & \\
\hline 0.1 & 0.1 & 1.8 & 2.7 & 2000 \\
\hline 0.3 & 0.9 & 0.6 & 1.2 & 2001 \\
\hline 0.2 & 0.3 & 2.1 & 4.5 & 2002 \\
\hline 0.2 & 0.8 & 0.6 & 1.8 & 2003 \\
\hline 0.1 & 0.3 & 1.4 & 2.9 & 2004 \\
\hline 0.3 & 0.8 & 2.5 & 4.1 & 2005 \\
\hline 0.3 & 1.0 & 3.2 & 5.1 & 2006 \\
\hline 0.5 & 0.9 & 3.0 & 4.7 & 2007 \\
\hline 0.6 & 1.6 & 7.3 & 9.0 & 2008 \\
\hline 3.1 & 2.0 & 17.5 & 14.7 & 2009 \\
\hline 3.1 & 2.0 & 18.5 & 19.6 & 2010 \\
\hline 3.7 & 5.3 & 28.2 & 23.8 & 2011 \\
\hline 7.0 & 3.3 & 28.7 & 11.3 & 2012 \\
\hline 6.4 & 5.5 & 33.4 & 24.6 & 2013 \\
\hline 6.3 & 12.9 & 36.6 & 35.9 & 2014 \\
\hline 8.7 & 10.3 & 25.2 & 25.1 & 2015 \\
\hline 1.4 & 1.7 & 28.3 & 34.6 & 2016 \\
\hline 3.4 & 1.3 & 32.6 & 9.6 & 2017 \\
\hline 2.5 & 2.8 & 15.1 & 13.1 & المتوسط \\
\hline
\end{tabular}


جلول 8. معادلات الاتجاه الزمنى العام لتطور متغيرات صادرات وواردات مصر إلى ومن العالم من محصول البلح خلال

(الفترة (2017-2000)

\begin{tabular}{|c|c|c|c|c|c|c|}
\hline $\mathbf{F}$ & $\mathbf{R}^{2}$ & التغير السنوي & المعادلة & المتغيرات & & المعادثة \\
\hline 27.6 & 0.63 & 0.13 & $\begin{array}{c}\hat{\mathbf{Y}}=-3.12+1.70 \mathbf{T}_{\mathbf{i}} \\
(-0.8)(5.3)^{* *}\end{array}$ & 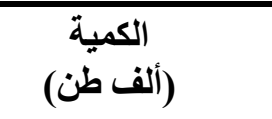 & & 5 \\
\hline 84.3 & 0.84 & 0.16 & $\begin{array}{c}\hat{\mathbf{Y}}=-7.35+2.36 \mathbf{T}_{\mathbf{i}} \\
(-2.6)^{*}(9.2)^{* *}\end{array}$ & (مليون دولار) & الصادرات & 6 \\
\hline 8.7 & 0.35 & 0.14 & $\begin{array}{c}\hat{\mathbf{Y}}=- \\
-0.941+0.397 \mathbf{T}_{\mathbf{i}} \\
(-0.6)(2.9)^{*}\end{array}$ & (ألف طنّ) & & 7 \\
\hline 19.4 & 0.55 & 0.16 & $\begin{aligned} \hat{\mathbf{Y}}= & -1.197+0.393 \mathbf{T}_{\mathbf{i}} \\
& (-1.2)^{*}(4.4)^{* *}\end{aligned}$ & 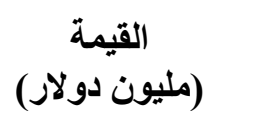 & الواردات & 8 \\
\hline
\end{tabular}

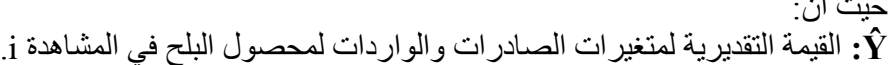

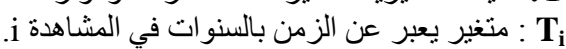

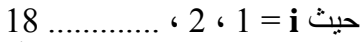
المصدر: جُمعت وحُسبت من الأرقام الواردة بجدول 7.

4- إنتاج أصناف غير جيدة وضعيفة الإنتاج.

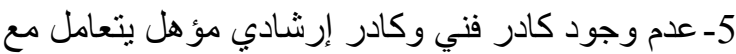
عمليات الخدمة بالطرق الصحيحة. 6- انعدام بر امج المكافحة المتكاملة للحشر ات و والأمر اضله. 7- اتباع الطرق التقليدية فى الحصاد. المشاكل التصديرية والتسويقية 1- إنتاج أصناف غير مطلوبة للتصدير. 2- انخفاض أسعار هذه الأصناف. 3- انخفاض القدرة التنافسية لهذه الأصناف في الأسواق الاصناف العالمية.

4- تدنى نسبة التصدير بالمقارنة بالإنتاج. 5- عدم تطبيق مواصفات الجودة و المو اصفات القياسية على محصول البلح عند التسويق. 6- ضعف عمليات الخدمة ما بعد الجنى خاصة التداول و التخزين الأمر الذي يقلل من القيمة التسويقية.

$$
\text { 7- ضعف شبكات التسويق المحلى و العالمى. }
$$

استر اتيجية تطوير قطاع النخيل فى مصر

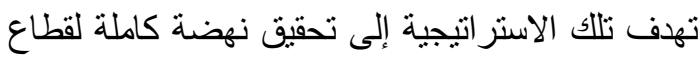

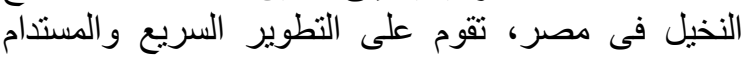

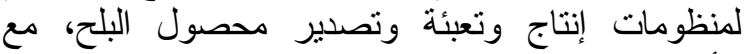
الأستفادة من المنتجات الثنانوية ومخلفات النخيل، مما سيعود

\section{تظور قيمة واردات مصر من العالم الخارجي}

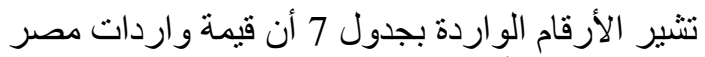

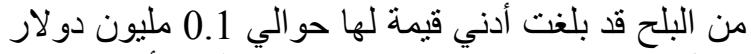
خلال عامي 2000-2004، في حين بلغت القالت أقصي قيمة

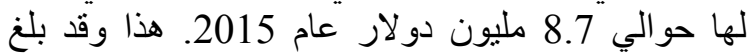
المنوسط العام لقيمة الواردات حو الي 2.7 ملئر مليون دولار خلال الفترة 2000-2017.

وتوضح المعادلة رقم 8 بجدول 8 الاتجاه الزمني العام

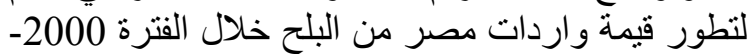

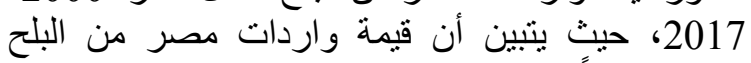
تتزايد سنوياً بمقدار معنوي إحصنيائيا بلغ حوالي 0.4

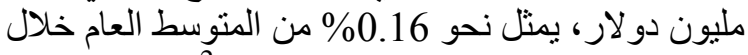
تللك الفترة. هذا وقد بلغ معامل التحديد

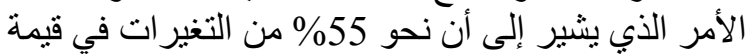

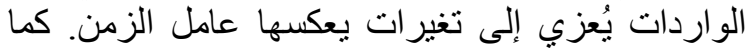
تثير قيمة F المحسوبة 19.4 إلى مدي مطابقة النموذج الئي المستخدم لطبيعة البيانات موضع القياس.

$$
\text { أهم المشاكل التي تواجه إنتاج نخيل البلح }
$$
المشاكل الإنتاجية 1- انتنسار سوسة النخيل في أنحاء مصر .

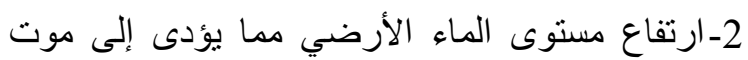

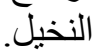

3- عدم الاهتمام بالعمليات الزر اعية المختلفة وخصوصاً التقليم (التكريم). 
4- إنشاء شراكة بين المصانع ووحدات التعبئة وكبار

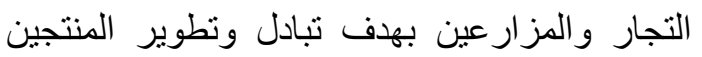
و التعرف على متطلبات السوق المحلى و الدولى.

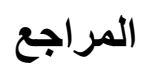

الجهاز المركزى للتعبئة العامة والاحصاء، اعداد متفرقة. سليم، أيمن شحاتة مصطقى (2008). دراسة اقتصادية

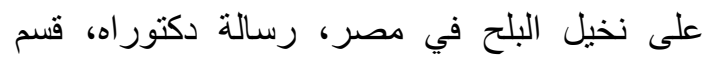
الاقتصاد الزر اعي، كلية الزر اعة، جامعة فئ بنها.

$$
\text { منظمة الأغذية والزراعة (الفاو). }
$$

وزارة الزراعة واستصلاح الأراضي (2018). الإدارة

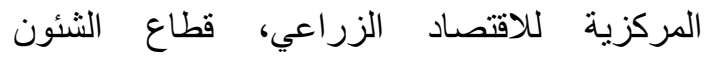
الاقتصادية.

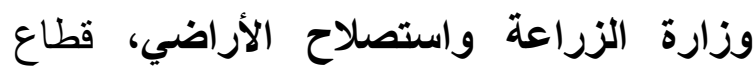

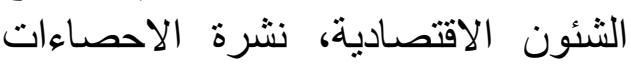
الزراعية (المحاصيل الصيفية والنيلية)، بيانات ثانوية غير منشورة، أعداد متفرقة. http://www.fao.org/faostat/en/\#data/TP
ولى الميزانية العامة للدولة والمصنعين و المستثرين و التجار وبصفة خاصة صغار المزارعين الطبقات الأكثر احتباجاً ولتحقيق ذلك اشتملت الأستراتيجية على:

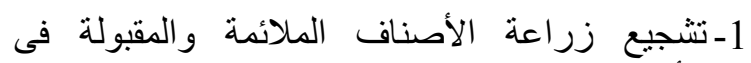

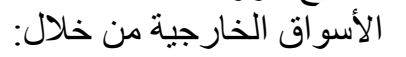

$$
\begin{aligned}
& \text { - نوجيه الإنتاج نحو هذه الأصناف. } \\
& \text { ـ ـقديم الدعم المالى لزر اعة هذه الأصناف. }
\end{aligned}
$$

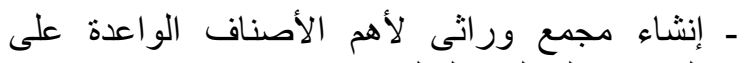

$$
\begin{aligned}
& \text { المستوى المحلى و العالمى. لأهى } \\
& \text { - تشجيع الأستثمار فى مجال نخيل البلح. }
\end{aligned}
$$

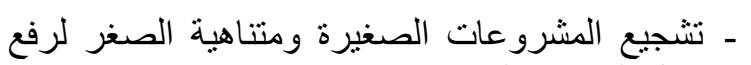

$$
\begin{aligned}
& \text { دخل المز ارع الصغير. } \\
& \text { 2- تنفيذ برنامج مكافحة متكاملة للأفات التى تصيب } \\
& \text { المحصول و النخيل وذللك باستخدام: } \\
& \text { - المكافحة الحيوية. } \\
& \text { - ـ استخدام المصائد الفرمونية لجذبة الحشرات. }
\end{aligned}
$$

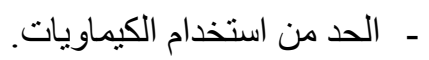




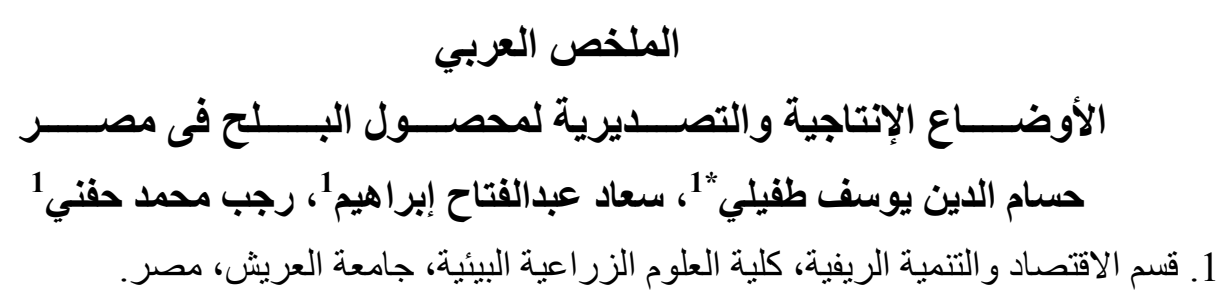

استهدف البحث التعرف على الوضع الإنتاجي والتصديري وأهم المشاكل التي تواجه محصول البلح وكيفية

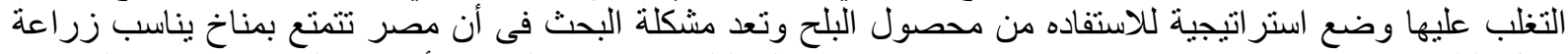
نخيل البلح، مما يتيح فرصة لإنتاج كميات كبيرة من محصول البلح وبجودة عالية. إلا أن هذه الميزة غير مستئ مستغلة حيث

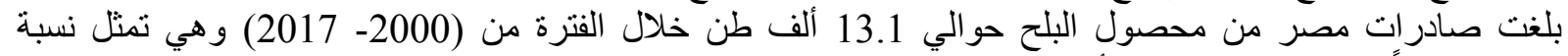

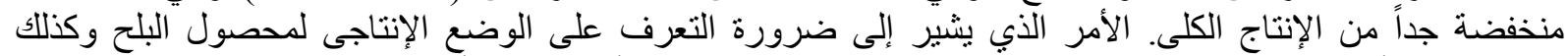

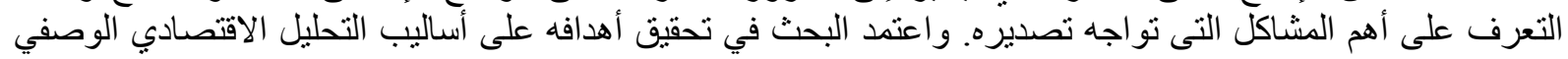

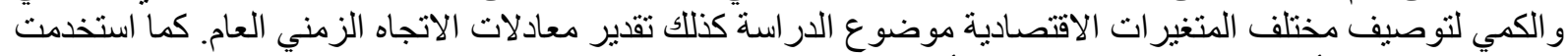

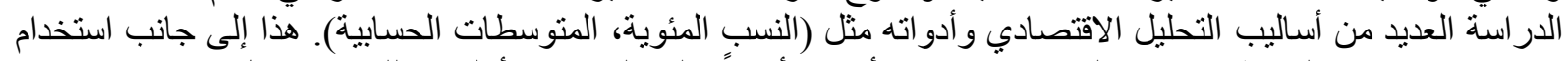

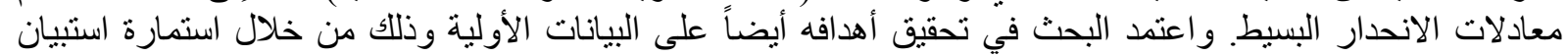

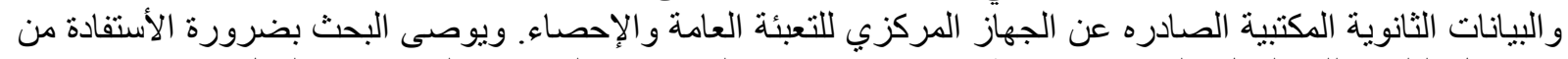

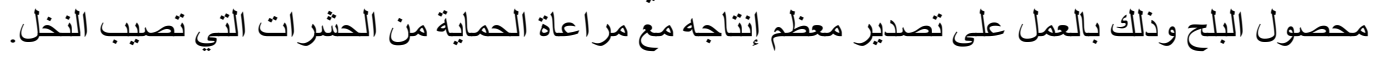
الكلمات الإسترشادية: نخيل البلح، التصدير، الإنتاج، مصر.

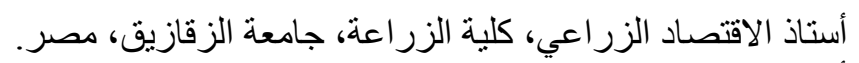

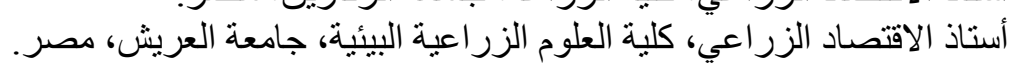

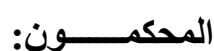

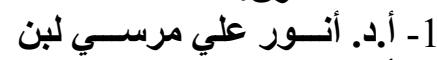

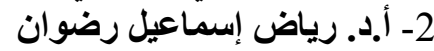

